\title{
Effects of Si-Jun-Zi decoction polysaccharides on cell migration and gene expression in wounded rat intestinal epithelial cells
}

\author{
L. Liu ${ }^{1}$, L. Han ${ }^{2}$, Daisy Y. L. Wong ${ }^{1}$, Patrick Y. K. Yue ${ }^{1}$, W. Y. Ha ${ }^{1}$, Y. H. Hu ${ }^{3}$, P. X. Wang ${ }^{2}$ and \\ Ricky N. S. Wong ${ }^{1,3} *$ \\ ${ }^{1}$ Research and Development Division, School of Chinese Medicine, Hong Kong Baptist University, Hong Kong \\ ${ }^{2}$ Immunology Laboratory, Guangzhou University of Traditional Chinese Medicine, Guangzhou, People's Republic of China \\ ${ }^{3}$ Department of Biology, Science Faculty, Hong Kong Baptist University, Kowloon Tong, Hong Kong
}

(Received 7 October 2003 - Revised 17 August 2004 - Accepted 4 September 2004)

\begin{abstract}
Si-Jun-Zi decoction (SJZD), a traditional Chinese herbal prescription, has been used clinically for treating patients with disorders of the digestive system. Previous studies indicated that the polysaccharides of SJZD (SJZPS) are the active components contributing towards its pharmacological effects in improving gastrointestinal function and immunity. However, the protective and restitutive effects on intestinal epithelial cells remain unknown. In the present study, SJZPS were first extracted and chemically characterized. Then their stimulatory and restitutive effects on intestinal epithelial cells (IEC-6 cells) were elicited by different in vitro models including migration of wounded IEC-6 cells and cell proliferation. Results indicated that SJZPS not only protects the cells against the harmful impairment of indomethacin but also enhances re-epithelialization of a wounded monolayer at an optimal dose of $100 \mu \mathrm{g} / \mathrm{ml}$ at $24 \mathrm{~h}$ incubation. To elucidate the modulatory effect of SJZPS on wounded IEC-6 cells at the molecular level, an oligonucleotide microarray was employed to study differential gene expression of SJZPS-treated IEC-6 cells and the candidate genes were validated by RT-PCR. There was increased expression of genes coding for ion channels and transporters, which are critical to cell migration and restoration of wounded intestinal cells, suggesting a possible mechanism for re-epithelialization. In conclusion, our data show for the first time that SJZPS can enhance intestinal restitution and protect against indomethacin-induced damage of intestinal epithelial cells. These findings provide new insight into the mechanism of action of a traditional Chinese herbal prescription, SJZD, in intestinal wound restitution.
\end{abstract}

Si-Jun-Zi decoction: Polysaccharides: IEC-6 cell: Microarray

The intestinal mucosal epithelium plays an important role in preventing translocation of deleterious substances or organisms present within the lumen of the gut and in preserving normal homeostasis (Dignass \& Podolsky, 1995). Impairment of the epithelial surface barrier may facilitate the penetration of harmful factors from the intestinal lumen, leading to acute and chronic inflammatory changes caused by the initiation of a complex network of immune responses. The inability to repair damage to the intestinal mucosal epithelium is a common physiological event that may account for numerous gastrointestinal diseases or disorders, such as infectious diarrhoea, gastrointestinal ulcer and inflammatory bowel disease. Indeed, the intestinal epithelium exerts enormous regenerative capabilities to allow rapid healing of injury by at least two different processes: migration and proliferation. Re-establishment from superficial injury can be achieved initially within minutes to hours by the migration of viable epithelial cells adjacent to or just beneath the injured surface to cover the denuded area, a process termed epithelial restitution or re-epithelialization (Lacy, 1988; Moore et al.
1989; McCormack et al. 1992). After sealing of the epithelial surface to regain its integrity, epithelial cell proliferation takes place to replenish the decreased cell pool (Dignass \& Podolsky, 1995).

Around $50 \%$ of the Western population relies on herbal medicines for the treatment or prevention of digestive disorders (Langmead \& Rampton, 2001). Si-Jun-Zi decoction (SJZD), a traditional Chinese herbal prescription, is well known for treating disorders of digestive function manifested by poor appetite, indigestion and watery stools or diarrhoea. It also has been used as a tonic supplement for health maintenance. It is formulated from four Chinese herbs: Dangshen (Codonopsis pilosula (Franch.) Nannf); Gancao (Glycyrrhizae uralensis Fisch.); Baizhu (Atractylodes macrocephala Koidz.); Fuling (Poria cocos (Schw.) Wolf), of which the polysaccharides are considered the main active components contributing towards its therapeutic effects. In vivo studies have shown that SJZD can improve intestinal mucosal immunofunction by counteracting the adverse effect of cyclophosphamide on intestinal mucosal-associated lymphoid

\footnotetext{
Abbreviations: ASIC1, acid-sensing ion channels, proton-gated cation channels; DMEM, Dulbecco's modified Eagle medium; FBS, fetal bovine serum; GAPDH, glyceraldehye3-phosphate dehydrogenase; JUND, JunD proto-oncogene; Kv4, neuronal delayed rectifier $\mathrm{K}^{+}$channel; MTT, 3-(4,5-dimethylthiozol-2-yl)-2,5-diphenyltetrazolium bromide; PBK, phosphorylase kinase catalytic subunit; RCK4, putative potassium channel subunit protein; RIIA, type I regulatory subunit of cAMP-dependent protein kinase; SJZD, Si-Jun-Zi decoction; SJZPS, polysaccharides of SJZD.

* Corresponding author: Dr Ricky N. S. Wong, fax +852 3411 5995, email rnswong@hkbu.edu.hk
} 
tissues of mice (Liu et al. 2000); improve intestinal disturbances to alleviate diarrhoea in rats caused by radiation (Chen \& $\mathrm{Fu}$, 1996); and ameliorate intestinal injury in scalded rats and prevent the translocation of intestinal bacteria (Guo et al. 2003). As SJZD is used clinically for treating patients with gastrointestinal disorders, some clinical studies have indicated that SJZD is effective in treating chronic gastritis and intestinal metaplasia (Zhong et al. 1997; Langmead \& Rampton, 2001).

With the advancement of molecular medicine, more evidencebased and scientific support has accumulated to strengthen the scientific foundation and promote the modernization of traditional Chinese medicine. Genome-wide expression monitoring of genes by microarray analysis seems to provide a holistic approach to examine the biochemical effects of Chinese medicines. This functional genomic approach has successfully revealed the possible mechanisms of action for some herbal extracts such as Ginkgo biloba (Watanabe et al. 2001), Coptidis rhizome (Iizuka et al. 2003), a preparation of eight different herbs (Bonham et al. 2002) and four other Chinese herbal extracts (Sadava et al. 2002). Recently, the mechanism of SJZD in human gastric cancer grafted onto nude mice was studied at the gene expression level (Zhao et al. 2002). Since migration of intestinal epithelial cells is the principal force behind early restitution of mucosal injury and the mechanism of action of the polysaccharides of SJZD (SJZPS) on intestinal function has not been elucidated, the aim of the present study was to characterize the effects of SJZPS on intestinal epithelial wound healing (restitution) in vitro. The non-transformed rat small intestinal epithelial cell line IEC-6 was used in this study because it is a common cell model for demonstrating the process of migration during early mucosal restitution (McCormack et al. 1992; Dignass \& Podolsky, 1995; Cario et al. 2000). The restitutive effect of SJZPS in the wound healing assay and its stimulatory and protective effects against indomethacin-induced damage in a proliferation assay were investigated. Furthermore, to elucidate the molecular mechanism of the modulatory effect of SJZPS on wounded IEC-6 cells, gene expression profiling with an oligonucleotide microarray was employed.

\section{Materials and methods}

Sources of IEC-6 cells and reagents

The intestinal epithelial cell line (IEC-6 cells; ATCC CRL 1592) was purchased from the American Type Culture Collection (Rockville, MD, USA) at passage 14 . This IEC-6 cell line originated from intestinal crypt cells, as judged by morphological and immunological criteria. The stock culture was maintained in a T-150 flask in Dulbecco's modified Eagle medium (DMEM) supplemented with $10 \%$ fetal bovine serum (FBS), $10 \mu \mathrm{g}$ insulin/ml and $50 \mu \mathrm{g}$ gentamicin sulphate $/ \mathrm{ml}$. The stock culture was incubated at $37^{\circ} \mathrm{C}$ in a humidified atmosphere of $95 \%$ air and $5 \% \mathrm{CO}_{2}$. The cells were sub-cultured once per week at a dilution of 1:20 and the medium was changed three times per week. In the experiments, cells at passage $15-20$ were taken up with $0.25 \%$ (w/v) trypsin/ 1 mM-EDTA in Hanks' basic salt solution without $\mathrm{Ca}$ and $\mathrm{Mg}$. All chemicals used in the study were purchased from Sigma (St. Louis, MO, USA) unless specified otherwise. DMEM, FBS, PBS, antibiotics, insulin and sodium pyruvate were obtained from Gibco (Invitrogen Life Technologies, Carlsbad, CA, USA).
Extraction and characterization of polysaccharides from Si-JunZi decoction

SJZD was derived from four herbs, Gancao (G. uralensis Fisch.), Dangshen (C. pilosula (Franch.) Nannf), Baizhu (A. macrocephala Koidz.) and Fuling (P. cocos (Schw.) Wolf), in a ratio of 1:2:2:2 by weight. SJZD was used for the preparation of SJZPS as described previously (Ou, 1993; Chun et al. 2002) with modification. Dried herbs $(70 \mathrm{~g})$ were soaked in distilled water for $30 \mathrm{~min}$ at room temperature and then extracted twice in boiling distilled water at $1: 8 \mathrm{w} /$ $\mathrm{v}$ for $4 \mathrm{~h}$. The fractions were combined and concentrated by rotary evaporation. The supernatant was recovered by centrifugation and then dialysed against running water for $2 \mathrm{~d}$. The extract was precipitated with ethanol to a final concentration of $60 \%(\mathrm{v} / \mathrm{v})$ at $4{ }^{\circ} \mathrm{C}$ overnight and the precipitate was pelleted by centrifugation. Then, the supernatant was concentrated by rotary evaporation, another ethanol precipitation performed to a final concentration of $80 \%(\mathrm{v} / \mathrm{v})$ and the precipitate obtained by centrifugation. The pellets from the two ethanol precipitations were combined, dissolved in distilled water and deproteinated by the Sevag method (Staub, 1965). The crude polysaccharide precipitate was extracted by shaking vigorously with five volumes of chloroform-n-butanol $(4: 1, v / v)$ for $20 \mathrm{~min}$. The extraction was repeated five more times and the polysaccharides were recovered by ethanol precipitation as stated earlier. Finally, the SJZPS were dissolved in distilled water and sterilized by filtration through a $0.2 \mu \mathrm{m}$ membrane.

The sugar content of the SJZPS was determined by colorimetry with 3,5-dinitrosalicylic acid (Miller, 1959). Glucose was used as standard. The total protein content of the deproteinated polysaccharides was assayed by the Lowry method using bovine serum albumin as protein standard (Lowry et al. 1951). The lipopolysaccharide content of SJZPS was determined by the Limulus amebocyte lysate kinetic assay. The sugar composition of SJZPS was analysed by HPLC after acid hydrolysis. Briefly, polysaccharides $\left(200 \mathrm{mg}\right.$ ) were hydrolysed with $2 \mathrm{M}-\mathrm{H}_{2} \mathrm{SO}_{4}$ at $100^{\circ} \mathrm{C}$ for $4 \mathrm{~h}$. The depolymerized polysaccharides containing the neutral sugars were neutralized with $\mathrm{NaB}(\mathrm{OH})_{4}$ to $\mathrm{pH}$ 7. The supernatant was collected by centrifugation and concentrated before HPLC analysis using an Alltech Prevail Amino column $(0.3 \mu \mathrm{m}$, $2.1 \mathrm{~mm} \times 150 \mathrm{~mm}$ ) and Alltech 2000 ELSD detector (Alltech Associates, Inc., Deerfield, IL, USA). Column temperature was maintained at $25^{\circ} \mathrm{C}$. Degassed acetonitrile-distilled water $(9: 1 \mathrm{v} /$ v) was used as the eluent at a flow rate of $0.3 \mathrm{ml} / \mathrm{min}$.

\section{Wounding assay}

The wounding assay was performed as described previously (McCormack et al. 1992). Briefly, Matrigel was diluted with cool serum-free medium at a dilution of 1:7 (v/v) and coated onto sixwell plates at room temperature for $1 \mathrm{~h}$. Excess diluted Matrigel was discarded. After washing twice with cool serum-free medium, the coated plates were ready for wounding assay. Briefly, IEC- 6 cells were seeded at a density of $6.25 \times 10^{4}$ cells in six-well plates and cultured in $10 \%$ FBS-supplemented DMEM for $24 \mathrm{~h}$. Then, the cells were washed with PBS and further cultured for another $24 \mathrm{~h}$ in serum-free medium. To initiate migration, the cell monolayer was scratched with a razor blade followed by washing with serum-free medium. Fresh serum-free medium containing SJZPS to a final concentration of $50,100,200,400$ or $800 \mu \mathrm{g} / \mathrm{ml}$ was then added and recovery of the wounded monolayers due to cell migration towards the denuded area was evaluated at intervals of 
8,16 and $24 \mathrm{~h}$. The area covered by the migrating cells was measured with an inverted phase-contrast microscope (model TMS; Nikon Corporation, Tokyo, Japan) and the images analysed using Motic Images Plus 2.0 software (Motic Instruments Inc., Richmond, Canada). The time-dependent effect of SZJPS on wounded IEC-6 cells expressed was as migration rate compared with the medium as control:

Migration rate $=\left[\left(\right.\right.$ Treatment $_{\text {area }}-$ Control $\left._{\text {area }}\right) /$ Control $\left._{\text {area }}\right]$

$$
\times 100 \% \text {. }
$$

\section{Determination of IEC-6 cell proliferation}

The dose effect of SJZPS on IEC-6 cell proliferation was determined by the 3-(4,5-dimethylthiozol-2-yl)-2,5-diphenyltetrazolium bromide (MTT) assay as described by Mosmann (1983) with modification. Briefly, IEC-6 cells were seeded at a density of $1 \times 10^{4}$ cells/well in 96-well plates and cultured in DMEM supplemented with $10 \%$ FBS for $24 \mathrm{~h}$. Then, cells were washed with PBS and cultured for a further $24 \mathrm{~h}$ in serum-free medium. The cultures were then supplemented with serum-free medium containing sterilized SJZPS at a final concentration of 50, 100, 200,400 or $800 \mu \mathrm{g} / \mathrm{ml}$ and subsequently incubated at $37^{\circ} \mathrm{C}$ for $24 \mathrm{~h}$. Two sets of positive control experiments were performed in parallel: one using $20 \mathrm{ng}$ epithelial growth factor/ $\mathrm{ml}$ and the other $10 \%$ FBS alone. Cell proliferation was measured using the Cell Proliferation Kit I (Roche Diagnostics Corp., Indianapolis, IN, USA) according to the manufacturer's instructions. The colour development from the tetrazolium compound, which is directly proportional to the number of viable cells in culture, was measured spectrophotometrically at $550 \mathrm{~nm}$ using an ELISA plate reader (Sunrise; Tecan Instruments, Maennedorf, Switzerland).

To examine the protective effect of SJZPS against indomethacin-induced damage of IEC-6 cells, indomethacin $(40 \mu \mathrm{M})$ and various concentrations of SJZPS $(50,100$ and $200 \mu \mathrm{g} / \mathrm{ml})$ were co-incubated with IEC- 6 cells that had been starved for $24 \mathrm{~h}$ in serum-free medium. After further incubation for $24 \mathrm{~h}$, the extent of cell proliferation was determined using the Cell Proliferation Kit I (Roche Diagnostics Corp.). All data are expressed as percentage relative viability: Relative viability $(\%)=$ $\left(\mathrm{OD}_{\text {experiment }} / \mathrm{OD}_{\text {control }}\right) \times 100 \%$, where $\mathrm{OD}$ is optical density.

\section{Gene expression profiling analysis}

IEC- 6 cells $\left(6.25 \times 10^{4}\right.$ cells $)$ were seeded in $10 \mathrm{~cm}$ Matrigel-coated Petri dishes and incubated in DMEM supplemented with $10 \%$ FBS in a humidified atmosphere of $95 \%$ air and $5 \% \mathrm{CO}_{2}$. After $72 \mathrm{~h}$, the cells became confluent, the medium was replaced by serum-free DMEM and incubation was continued for a further $24 \mathrm{~h}$. Confluent cells were wounded vertically, horizontally and diagonally using a multi-channel pipette with attached yellow tips (eight channels). The distance between each line of denuded area was about $0.9 \mathrm{~cm}$. Cells were washed with PBS. SJZPS, at a final concentration of $100 \mu \mathrm{g} / \mathrm{ml}$, was added and the cells were incubated for another $24 \mathrm{~h}$. A control was given the same wounding but without SJZPS treatment. The same batch of IEC-6 cells at passage 18 was used for three independent sets of microarray experiments.

Total cellular RNA was isolated from the control and SJZPS-treated IEC-6 cells using the Atlas ${ }^{\mathrm{TM}}$ Glass Total RNA Isolation Kit (Clontech, Palo Alto, CA, USA) according to the manufacturer's instructions. The quantity and quality of RNA were determined on the basis of spectrometric measurements $(260$ and $280 \mathrm{~nm})$ and electrophoresis in $1.0 \%$ Tris-boric acid-EDTA agarose gels, respectively.

cDNA probes for microarray analysis were prepared using the Atlas $^{\text {TM }}$ PowerScript $^{\text {TM }}$ Fluorescent Labeling Kit (Clontech). Briefly, $8 \mu \mathrm{g}$ total RNA isolated from control and SJZPS-treated cells were primed separately with $2 \mu$ l CDS (cDNA synthesis) primer mix and $1 \mu \mathrm{l} \mathrm{cDNA}$ synthesis control, incubated at $70^{\circ} \mathrm{C}$ for $5 \mathrm{~min}$ in a thermal cycler (PTC- $100^{\circledR}$; MJ Research, Inc., Watertown, MA, USA) and cooled to $48^{\circ} \mathrm{C}$. Then, a master mix containing $4 \mu \mathrm{l} 5 \times$ first-strand buffer, $2 \mu \mathrm{l} 10 \times$ dNTP, $2 \mu \mathrm{l}$ dithiothreitol $(100 \mathrm{~mm}), 1 \mu \mathrm{l}$ deionized water and $1 \mu \mathrm{l}$ PowerScript Reverse Transcriptase was mixed with the primed RNA and incubated at $48^{\circ} \mathrm{C}$ for $1 \mathrm{~h}$. The reaction was stopped by heating at $70^{\circ} \mathrm{C}$ for $5 \mathrm{~min}$. Then, the tubes were cooled to $37^{\circ} \mathrm{C}$ and $0 \cdot 2 \mu \mathrm{l}$ RNase $\mathrm{H}(10 \mathrm{U} / \mu \mathrm{l})$ was added, followed by an additional incubation at $37^{\circ} \mathrm{C}$ for $15 \mathrm{~min}$. The reaction was then stopped by adding $0.5 \mu \mathrm{l} 0.5 \mathrm{M}$-EDTA, $\mathrm{pH} 8.0$ and the transcribed cDNA was purified by QuickClean ${ }^{\mathrm{TM}}$ Purification Resin (Clontech). Newly synthesized cDNA was precipitated with sodium acetate-absolute ethanol at $-20^{\circ} \mathrm{C}$ for $1 \mathrm{~h}$ and collected by centrifugation at $12000 \mathrm{rpm}$ for $20 \mathrm{~min}$. cDNA pellets were washed once with $70 \%$ ethanol and re-suspended in $10 \mu l 2 \times$ fluorescent labelling buffer (Clontech). Then the control and SJZPS-treated cDNAs were mixed with $0.5 \mu \mathrm{l}$ coupling reaction control oligos (Clontech) and subsequently coupled with $10 \mu \mathrm{l} 5 \mathrm{mM}-\mathrm{Cy} 5$ and Cy3 reactive dyes (Amersham Pharmacia, Piscataway, USA, $\mathrm{NJ})$, respectively, at $24^{\circ} \mathrm{C}$ for $1 \mathrm{~h}$. The labelled probes were precipitated and collected by the same procedure as mentioned earlier. Finally, the pellets were dissolved in $100 \mu \mathrm{l}$ sterile water (Clontech). Unincorporated reactive dye and other impurities were removed on a Microcon YM-30 column (Millipore, Billerica, MA, USA).

Cy5 (control) and Cy3 (SJZPS-treated) labelled probes were combined and mixed with GlassHyb hybridization solution (Clontech) in the ratio suggested by the company. Finally, the probe mixture was hybridized at $50^{\circ} \mathrm{C}$ overnight to the Atlas ${ }^{\mathrm{TM}}$ Glass Rat 1.0 Microarray (Clontech), which includes 1081 rat genes (80-mer oligo array), nine housekeeping genes, negative and positive controls. Thereafter, the microarrays were washed once in GlassHyb washing solution (Clontech), twice in GlassHyb washing solution diluted with $1 \times$ standard saline citrate and once in GlassHyb washing solution diluted with $0.1 \times$ standard saline citrate; each washing was for $10 \mathrm{~min}$ at room temperature. The hybridized arrays were spun dry prior to scanning.

Hybridized arrays were scanned using the ScanArray 5000 confocal laser scanner (Packard BioChip/GSI Lumonics, Billerica, MA, USA). To get the best-fit image, laser power and PMT (photomultiplier tube) voltage were adjusted manually to minimize background and saturated spots. Cy5 and Cy3 signal intensities of each spot were obtained using QuantArray Analysis Software (Packard BioChip/GSI Lumonics). Comparisons were made between the normal (Cy5) and SJZPS-treated IEC-6 cells (Cy3) from the same microarray. The signal intensities of each spot were corrected by subtracting local background signals. Then the Cy 3 and $\mathrm{Cy} 5$ signal intensities of each spot were further normalized by taking the total averaged signal intensities across all spots in the microarray to be equal for both channels (Hegde et al. 2000). To eliminate any unreliable data, spots were screened by first setting a threshold of minimum acceptable signal 
(background plus two standard derivations) to eliminate expression ratios of extremely high or low spots due to an undetectable signal in either channel and, second, performing visual inspection to eliminate any irregular spots. The genuine spots were subjected to calculation for the fold change (Cy3:Cy5). Differential gene expression was considered up- or down-regulated if the averaged ratio (Cy3:Cy5) between the two conditions was $>1.5$ or $<-1.5$, respectively.

\section{Validation of candidate genes by semi-quantitative RT-PCR}

Semi-quantitative RT-PCR was used to verify microarray data of the selected genes. Glyceraldehye-3-phosphate dehydrogenase (GAPDH) primers were used to compare and monitor the efficiency of cDNA synthesis between different samples. The primers were as follows: GAPDH sense primer AAG ATT GTC AGC AAT GCA TCC, antisense primer ACA GTC TTC TGA GTG GCA GTG A; phosphorylase kinase catalytic subunit (PBK) sense primer TCA CAG AAA CCA GCC CTT TAC C, antisense primer CAG GCG GTG ATG GCA AGG; JunD proto-oncogene (JUND) sense primer ACC CTC AAA AGC CAG AAC ACC, antisense primer CGC TCG GGC TCA ATA CGC; putative potassium channel subunit protein (RCK4) sense primer ATG CTG AAG CCC GAG AGA GAC, antisense primer TCG TGT GCT GTT ATC TGT GTG C; type I regulatory subunit of cAMPdependent protein kinase (RIIA) sense primer TGG TGA AAT TGC CCT GCT GAT G, antisense primer ACT GCT GGA TGT TTC GCT TGA G; neuronal delayed rectifier $\mathrm{K}^{+}$channel (Kv4) sense primer TTC ACA CTG CCA CCC TCT TCC, antisense primer TGG TCA CAC TGG AGC TAC ACA C. RT-PCR was carried out according to the manufacturer's instructions. Briefly, cDNA templates for RT-PCR were synthesized from $1 \mu \mathrm{g}$ total RNA using the ThermoScript ${ }^{\mathrm{TM}}$ RT-PCR system (Invitrogen) and oligo-dT primer. PCR mixtures (final volume $50 \mu \mathrm{l}$ ) contained $100 \mathrm{ng}$ cDNA template, $0 \cdot 2 \mu \mathrm{M}$ of each primer, $0.2 \mathrm{~mm}$ of each dNTP, $1 \times$ Taq buffer (Pharmacia), $1.5 \mathrm{~mm}$ $\mathrm{MgCl}_{2}$ and $1 \mathrm{U}$ Taq DNA polymerase (Pharmacia). The reactions went through a touchdown cycle of $94^{\circ} \mathrm{C}$ for $5 \mathrm{~min}$; then fifteen cycles at $94^{\circ} \mathrm{C}$ for $1 \mathrm{~min}, 65^{\circ} \mathrm{C}$ for $1 \mathrm{~min}$ (minus $1{ }^{\circ} \mathrm{C}$ per cycle) and $72^{\circ} \mathrm{C}$ for $1 \mathrm{~min}$; then fifteen to twenty cycles of $94^{\circ} \mathrm{C}$ for $30 \mathrm{~s}, 55^{\circ} \mathrm{C}$ for $30 \mathrm{~s}$ and $72^{\circ} \mathrm{C}$ for $1 \mathrm{~min}$; and a final extension at $72^{\circ} \mathrm{C}$ for $10 \mathrm{~min}$. Reactions were performed in a PTC-200 ${ }^{\circledR}$ thermal cycler (MJ Research Inc.). PCR products were analysed by electrophoresis in $1.5 \%$ agarose gel and Kodak 1D Image Analyis Software (Rochester, NY, USA) was used for the densitometric analysis. Due to variations in abundance of the different mRNA in the cell, the PCR cycles (Tsien \& Tsien, 1990; McCormack et al. 1998) and different titrations of the RT reaction (equal to $100 \mathrm{ng}, 500 \mathrm{ng}$ and $1 \mu \mathrm{g}$ total RNA) were performed in duplicate to ensure that the PCR reaction was in the linear range.

\section{Statistical analysis}

Data are expressed as mean and standard deviation. Significance of differences among groups (e.g. among different concentrations of SJZPS and the control) were tested by one-way ANOVA. Dunnett's post hoc procedure was used for post hoc testing; Dunnett's test compares the mean of each treatment group (e.g. SJZPS-treated cells) with that of a designated control. The effect of both incubation time intervals (time-dependent effect) and SJZPS concentration (dose-dependent effect) on cell migration was analysed by two-way ANOVA, followed by a multiple post hoc test using least significant difference. Differences were considered significant if $P<0.05$. SPSS 10.0 software (SPSS Inc., Chicago, IL, USA) was used to perform all calculations.

\section{Results}

Extraction and characterization of polysaccharides from Si-JunZi decoction

The total polysaccharides from SJZD were successfully extracted and chemically characterized. As shown in Table 1, SJZPS were composed of $51.82 \%$ total sugar and $37.5 \%$ protein; no lipopolysaccharides were detected. In terms of sugars, the composition of SJZPS was glucose $(44.61 \%)$, galactose $(33.96 \%)$, arabinose $(10.85 \%)$, rhamnose $(5.26 \%)$, xylose $(4.84 \%)$, mannose $(0.46 \%)$ and fructose $(0.02 \%)$ as determined by HPLC analysis. These results reveal that glucose and galactose are the main components of SJZPS.

Effect of polysaccharides from Si-Jun-Zi decoction on cell migration of wounded IEC-6 cells

A cell migration assay was used to mimic the early stage of intestinal epithelial restitution in vitro, in which the migration rate of IEC-6 cells after wounding was determined (Table 2). In addition, the dose effect of SJZPS and the incubation time for re-epithelialization of wounded IEC- 6 cells were evaluated. Concerning the time effect, significant re-epithelialization of the wounded IEC6 cells was observed $24 \mathrm{~h}$ after the addition of medium as control or SJZPS. However, the migration rate in the control group was much lower than that in the SJZPS-treated groups. Concerning the dose effect, SJZPS at a final concentration of $100 \mu \mathrm{g} / \mathrm{ml}$ was the optimal dose for stimulation of epithelial cell restitution in terms of cell migration towards the denuded area in vitro. Stimulation of epithelial restitution was increased by 38.45 , 102.39 and $132.74 \%$ at 8,16 and $24 \mathrm{~h}$, respectively, compared with the control.

Protective effect of polysaccharides from Si-Jun-Zi decoction on IEC-6 cells

We examined the relative viability of IEC- 6 cells after treatment with various concentrations of SJZPS ranging from 50 to $800 \mu \mathrm{g} / \mathrm{ml}$ in the proliferation assay (Fig. 1). The results show that SJZPS significantly enhanced the growth of IEC-6 cells by more than $40 \%$ at the optimal dose of $100-200 \mu \mathrm{g} /$ $\mathrm{ml}$. Indomethacin, a common non-steroidal anti-inflammatory

Table 1. The composition and sugar content analysis of the polysaccharides of Si-Jun-Zi decoction

\begin{tabular}{lc}
\hline Total sugar (wt \%) & 51.82 \\
Protein (wt \%) & 37.50 \\
Lipopolysaccharides & ND \\
Sugar components (mol \%) & \\
$\quad$ Glucose & 44.61 \\
Galactose & 33.96 \\
Arabinose & 10.85 \\
Rhamnose & 5.26 \\
Xylose & 4.84 \\
Mannose & 0.46 \\
Fructose & 0.02 \\
\hline ND, not detected. &
\end{tabular}


Table 2. The restitutive effect of the polysaccharides of Si-Jun-Zi decoction (SJZPS) on the migration of IEC-6 cells upon injury. Various concentrations of SJZPS were used to treat the wounded IEC- 6 cells and the migration area for each group of SJZPS-treated cells was monitored at 8,16 and $24 \mathrm{~h}$. Values are means with their standard deviation from three separate experiments. Migration rate at each time interval is expressed as a percentage of the control

\begin{tabular}{|c|c|c|c|c|c|c|c|c|c|}
\hline \multirow[b]{3}{*}{$\begin{array}{l}\text { SJZPS concentration } \\
(\mu \mathrm{g} / \mathrm{ml})\end{array}$} & \multicolumn{9}{|c|}{ Migration area $\left(\mathrm{mm}^{2}\right)$ at different intervals } \\
\hline & \multicolumn{3}{|c|}{$8 \mathrm{~h}$} & \multicolumn{3}{|c|}{$16 \mathrm{~h}$} & \multicolumn{3}{|c|}{$24 \mathrm{~h}$} \\
\hline & Mean & SD & $\begin{array}{l}\text { Migration } \\
\text { rate }(\%)\end{array}$ & Mean & SD & $\begin{array}{l}\text { Migration } \\
\text { rate }(\%)\end{array}$ & Mean & SD & $\begin{array}{l}\text { Migration } \\
\text { rate (\%) }\end{array}$ \\
\hline Control & 141.9 & $16 \cdot 5$ & - & $223 \cdot 1$ & $25 \cdot 0$ & - & $708 \cdot 6$ & 148.5 & - \\
\hline 50 & $136 \cdot 6$ & $23 \cdot 2$ & 3.8 & $250 \cdot 3$ & $11 \cdot 6$ & $12 \cdot 2$ & $890 \cdot 1^{\star}$ & $130 \cdot 5$ & $25 \cdot 7$ \\
\hline 200 & $172 \cdot 1$ & 44.9 & $21 \cdot 3$ & $321 \cdot 2$ & $35 \cdot 2$ & 44.0 & $1293 \cdot 0^{\star \star \star}$ & $116 \cdot 8$ & 82.5 \\
\hline 400 & $174 \cdot 6$ & 8.9 & $23 \cdot 1$ & $350 \cdot 2$ & $62 \cdot 0$ & $57 \cdot 0$ & $1485 \cdot 0^{\star \star \star}$ & 171.5 & 109.6 \\
\hline 800 & $204 \cdot 6^{\star \star \star}$ & $72 \cdot 2$ & $44 \cdot 2$ & 443.4 & $162 \cdot 3$ & $98 \cdot 8$ & $1266 \cdot 5^{\star \star \star}$ & 237.6 & 78.7 \\
\hline
\end{tabular}

Least significant difference test between means (two-way ANOVA): ${ }^{\star} P<0.01,{ }^{\star \star \star} P<0.001$ with regard to control values.

drug that causes inhibition of re-epithelialization, was used to study the protective effect of SJZPS on IEC-6 cells (Fig. 2). Indomethacin alone induced nearly $40 \%$ inhibition of cell growth in comparison with the control. However, addition of SJZPS at a concentration of $100 \mu \mathrm{g} / \mathrm{ml}$ produced $30 \%$ more viable IEC-6 cells than the indomethacin treatment.

Gene expression profiling of IEC-6 cells upon induction with polysaccharides from Si-Jun-Zi decoction

To explore the differential gene expression upon induction with SJZPS, DNA microarray analysis was performed. Wounded IEC-6 cells treated with $100 \mu \mathrm{g}$ SJZPS/ml for $24 \mathrm{~h}$ were subjected to the Atlas Glass Rat 1.0 Microarray, which included nine housekeeping genes, negative and positive controls and a total of 1081 rat genes. Three sets of microarray hybridization experiments were performed, and the genes up- and down-regulated in response to SJZPS induction are shown in Table 3. These genes could be classified into different categories, mainly related to ion channels such as voltage-gated ion channels, gradientdriven transporters, calcium-modulating ion channel and calcium-binding proteins, transcription factors, intracellular

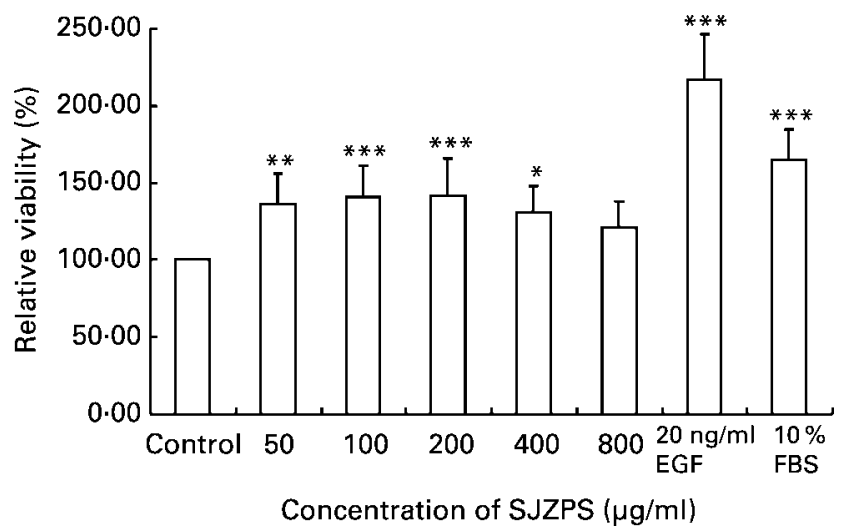

Fig. 1. Dose effect of the polysaccharides of Si-Jun-Zi decoction (SJZPS) on proliferation of IEC- 6 cells. 'Control' represents the medium as control; positive controls are $20 \mathrm{ng}$ epithelial growth factor (EGF)/ml and $10 \%$ fetal bovine serum (FBS). Values are means and standard deviation shown by vertical bars for three separate experiments. Statistical analysis was performed by one-way factorial ANOVA $(P<0.0001)$ with Dunnett's post hoc test. Significant difference v. control medium: ${ }^{\star} P<0.05,{ }^{\star \star} P<0.01,{ }^{\star} P<0.001$. SJZPS significantly enhances the growth of IEC- 6 cells by more than $40 \%$ at the optimal dose of $100-200 \mu \mathrm{g} / \mathrm{ml}$. kinase members and G-proteins. In particular, six genes, those coding for $J U N D$, phosphorylase B kinase, protein kinase type $1, \mathrm{~K}^{+}$voltage-gated channel, $\mathrm{K}^{+}$inwardly-rectifying channel and $\mathrm{K}^{+}$channel protein CDRK, were considered as up-regulated (Cy3:Cy5 >1.5). Five genes, those coding for $\gamma$-aminobutyric acid transporter, solute carrier family 6 (serotonin transport), neural visinin-like $\mathrm{Ca}^{2+}$-binding protein type 2 and 3, and Rasrelated GTP-binding protein 4b, were down-regulated (Cy3:Cy5 $<0 \cdot 6$ ) (Table 3). Besides, three additional genes, those coding for $\mathrm{K}^{+}$channel 1, acid-sensing ion channels, proton-gated cation channels (ASIC1) and metabotropic glutamate receptor 2, with expression ratio of 1.4-fold were also selected and considered as marginal candidate genes. The expression levels of $K^{+}$channel 1 and ASIC1 proton-gated cation channels were confirmed by RT-PCR.

\section{Confirmation of microarray data by RT-PCR}

Among the up-regulated genes found in the microarray study, the following were chosen for confirmation by semi-quantitative RTPCR: PBK (accession no. M73808); JUND (accession no. D26307); RCK4 (accession no. X16002); RIIA (accession no. M17086); and Kv4 (accession no. M68880). Because of the variations in abundance of mRNA of different genes in the cell, the

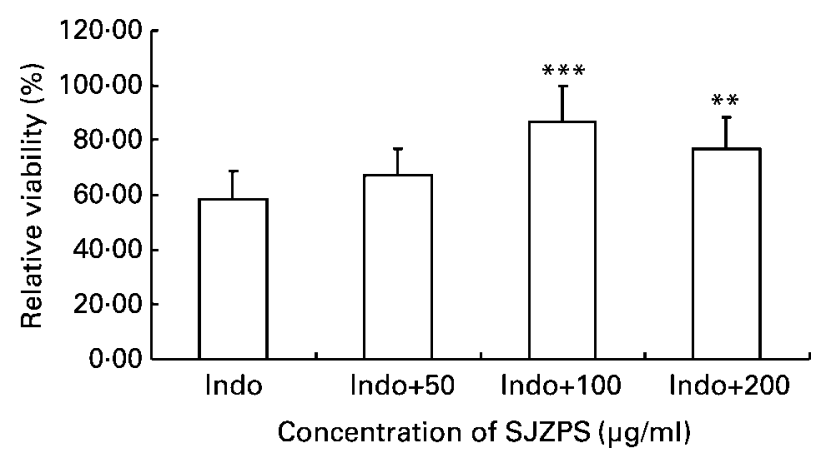

Fig. 2. Mucosal restitution effect of the polysaccharides of Si-Jun-Zi decoction (SJZPS) on indomethacin (Indo)-treated IEC-6 cells. Values are means and standard deviation shown by vertical bars for three separate experiments. Statistical analysis was performed by one-way factorial ANOVA $(P<0.0001)$ with Dunnett's post hoc test. Significant difference v. indomethacin treatment: ${ }^{\star \star} P<0.01,{ }^{\star \star \star} P<0.001$. SJZPS at the concentration of $100 \mu \mathrm{g} / \mathrm{ml}$ shows the best restorative effect on IEC- 6 cells, resulting in approximately $86 \%$ relative viability. 
Table 3. IEC-6 cells seeded in a Matrigel-coated Petri dish were incubated in Dulbecco's modified Eagle medium supplemented with $10 \%$ fetal bovine serum in a humidified atmosphere with $95 \%$ air and $5 \% \mathrm{CO}_{2}$ for $72 \mathrm{~h}$, followed by $24 \mathrm{~h}$ serum-free incubation. Confluent cells were mechanically wounded with the tip of a multi-channel pipette. Cells were washed with PBS and incubated with $100 \mu \mathrm{g} / \mathrm{ml}$ polysaccharides of Si-Jun-Zi decoction (SJZPS) for $24 \mathrm{~h}$. Total RNA was extracted, reverse-transcribed into cDNA labelled with Cy5 (for control) and Cy3 (for treatment) and hybridized to the Altas ${ }^{\mathrm{TM}}$ Glass Rat $1.0 \mathrm{Microarray}$ (Clontech, Palo Alto, CA, USA). The average gene expression ratio of control medium and SJZPS-treated IEC-6 cells from three independent microarray experiments was calculated. Genes with an expression ratio $>1.5$ or $<0.6$ were selected as candidate genes. '\#' indicates that the gene is a marginal candidate. Genes marked with '*' had their expression level confirmed by RT-PCR

Genes expressed differentially in wounded IEC-6 cells in response to SJZPS induction

GenBank accession no.

Cy3:Cy5

Transcription factors

JunD proto-oncogene*

D26307

Intracellular kinase network members

Phosphorylase B kinase catalytic subunit ${ }^{*}$

Protein kinase, cAMP-dependent, regulatory, type $1^{*}$

M73808

M17086

Voltage-gated ion channels

Potassium voltage-gated channel, shaker-related subfamily, member $4^{\star}$

$\mathrm{X} 16002$

L35771

M77482

M68880

Potassium inwardly-rectifying channel, subfamily J, member 5

Potassium channel protein CDRK

Potassium channel $1^{*} \dagger$

U94403

ASIC1 proton-gated cation channel $†$

GABA transporter

Solute carrier family 6 (neurotransmitter transporter, serotonin),

U94403
U28927

M79450

member 4 (5-hydroxytryptamine (serotonin) transporter)

Calcium-modulated ion channels

Metabotropic glutamate receptor 2 (GRM2; MGLUR2)†

M92075

Calcium-binding proteins

Neural visinin-like $\mathrm{Ca}^{2+}$-binding protein type 2

Neural visinin-like $\mathrm{Ca}^{2+-}$ binding protein type 3

D13125

G-protein

Ras-related GTP-binding protein $4 b$

D13126

GABA, $\gamma$-aminobutryic acid.

*Genes had their expression level confirmed by RT-PCR

†Gene is a marginal candidate.

PCR cycles (Tsien \& Tsien, 1990; McCormack et al. 1998) and titration of the RT reaction (equal to $100 \mathrm{ng}, 500 \mathrm{ng}$ and $1 \cdot \mu \mathrm{g}$ total RNA) were performed in duplicate to ensure that PCR was in the linear range (data not shown). The relative expression ratios of selected genes were normalized with regard to ribosomal gene $S 29$ (Fig. 3). The results indicate that the expression patterns of the selected genes as determined by DNA microarray and RTPCR were highly comparable.

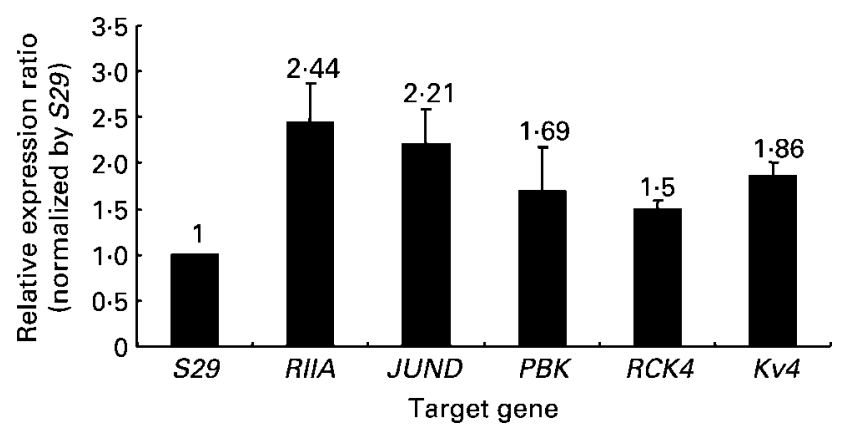

Fig. 3. Confirmation of microarray data by semi-quantitative RT-PCR. cDNA was synthesized from $1 \mu \mathrm{g}$ RNA in duplicate. The expression ratio for type I regulatory subunit of cAMP-dependent protein kinase (RIIA) was observed at 12 cycles; JunD proto-oncogene (JUND) and phosphorylase kinase catalytic subunit $(P B K)$ were observed at 25 cycles; putative potassium channel subunit protein $(R C K 4)$ and neuronal delayed rectifier $K^{+}$channel $(K v 4)$ were observed at 35 cycles. Expression of all target genes was normalized by that of the gene coding for ribosomal protein S29 (S29). All genes were found to be up-regulated and the expression patterns were comparable to the microarray data.

\section{Discussion}

The use of herbal medicinal decoctions to modulate body homeostasis is a common practice among the Chinese. Si-Jun-Zi decoction, a traditional Chinese herbal prescription formulated by four Chinese herbs (Dangshen, Gancao, Baizhu and Fuling) has been used to treat disorders of the digestive system with symptoms such as poor appetite, indigestion and diarrhoea. Previous studies showed that many of its active constituents, in particular the polysaccharides, shared anti-tumour and immunostimulatory effects (Haranaka et al. 1985; Lin, 1988; Xu et al. 1994; Liu et al. 2000; Chang, 2002; Kiyohara et al. 2002). However, the protective effect of the polysaccharides of SJZD on the gastrointestinal epithelium had not been studied previously.

To elicit the gastrointestinal restitution effect of SJZPS, we performed several lines of bioassay. First, the proliferative effect of SJZPS on IEC-6 cells was demonstrated by MTT assay (Fig. 1). It can be inferred from the observations that replacing lost cells through cell proliferation can enhance restitution of damaged epithelial cells. Second, SJZD was found to protect IEC-6 cells from indomethacin-induced injury. Indomethacin, a cyclooxygenase inhibitor, is the most potent of the non-steroidal anti-inflammatory drugs and can cause gastroduodenal mucosal injury, ulceration and delay ulcer healing (Larkai et al. 1987). Previous studies showed that the ulcerogenic action of indomethacin could be attributed to the increase of intestinal permeability (Kimura et al. 1998), influx of neutrophils (Bjarnason et al. 1993) and prostaglandin depletion (Ding et al. 1998). Indomethacin has a 
pronounced effect on human intestinal mucosal injury (Li et al. 1999; McCormack et al. 1999), whereas SJZPS can restore the recovery of IEC-6 cells after treatment with indomethacin. This suggests that SJZPS can exert a certain repairing ability in the early phase of mucosal restitution. Third, the gastrointestinal restitution effect of SJZPS was further demonstrated by the in vitro migration assay (McCormack et al. 1993). Accordingly, replacement of lost cells or tissues is partly achieved by cell migration (Tarnawski et al. 1995). In the current study, the confluent monolayer of IEC-6 cells was scratched with a razor blade and the cells were allowed to migrate towards the denuded area. The results indicated that SJZPS could enhance migration of the IEC-6 cells; the most effective dosage was $100 \mu \mathrm{g} / \mathrm{ml}$.

To gain further insight into the modulating effect of SJZPS during intestinal epithelial restitution, DNA microarray technology was applied to decipher the biological pathways involved. Among the 1081 genes profiled in the microarray experiments, the candidate genes that were significantly up-regulated coded for voltage-gated ion channel, voltage-gated $\mathrm{K}^{+}$channel, inwardly-rectifying $\mathrm{K}^{+}$channel, $\mathrm{K}^{+}$channel protein CDRK (Circumvallate Papilla Delayed Rectifier $\mathrm{K}^{+}$channel), $\mathrm{K}^{+}$channel 1 and gradient-driven transporter (proton-gated cation channel, ASIC1). Previous reports have shown that $\mathrm{K}^{+}$channels play a very important role in the migration of intestinal epithelial cells through the modulation of membrane potential and $\mathrm{Ca}^{2+}$ influx (Wang et al. 2000; Rao et al. 2002). In addition, $\mathrm{Ca}^{2+}$ is a wellknown secondary messenger in many cellular activities and biochemical pathways. Alteration of cytosolic $\mathrm{Ca}^{2+}$ concentration would determine the response of cells to the surrounding environment, sequential signal transduction linked with the surface receptors and hence the final behaviours of the cells. Basically, in the present study, the expression of $\mathrm{K}^{+}$channel genes due to the effect of SJZPS acting on wounded IEC-6 cells correlated positively with the cell migration assay.

The activities of the voltage-gated $\mathrm{K}^{+}$channels that regulate membrane potential determine the cytosolic free $\mathrm{Ca}^{2+}$ concentration by regulating $\mathrm{Ca}^{2+}$ influx. IEC- 6 cells are a type of nonexcitable cell that does not express L-type voltage-dependent $\mathrm{Ca}^{2+}$ channels (Himmel et al. 1993; Nilius et al. 1997). Thus the cytosolic free $\mathrm{Ca}^{2+}$ concentration is regulated by the influx of extracellular $\mathrm{Ca}^{2+}$ through passive $\mathrm{Ca}^{2+}$ leakage, receptoroperated $\mathrm{Ca}^{2+}$ channels, stored-operated $\mathrm{Ca}^{2+}$ channels and the $\mathrm{Ca}^{2+}$ released from intracellular organelles such as endoplasmic and sarcoplasmic reticulum (Quaroni et al. 1979; Tsien \& Tsien, 1990; Himmel et al. 1993; Putney \& Bird, 1993; Bilato et al. 1995; Pauly et al. 1995; Nilius et al. 1997; Moore et al. 1998). Moreover, the magnitude of $\mathrm{Ca}^{2+}$ influx has been found to depend on both the transmembrane $\mathrm{Ca}^{2+}$ gradient and the membrane potential (Fleischmann et al. 1993; Bilato et al. 1995). Previous studies have also indicated that the membrane potential of eukaryotic cells is basically controlled by the number and functional ability of membrane $\mathrm{K}^{+}$channels (Fleischmann et al. 1993; Bilato et al. 1995). When the gene expression of $\mathrm{K}^{+}$channels is being induced, the sequential increase of available $\mathrm{K}^{+}$channels and their functional ability result in membrane hyperpolarizaton. Since membrane potential is the major driving force controlling $\mathrm{Ca}^{2+}$ influx, this tendency increases the magnitude of $\mathrm{Ca}^{2+}$ influx into the cells and finally contributes to the elevation of cytosolic $\mathrm{Ca}^{2+}$ concentration. Raising cytosolic free $\mathrm{Ca}^{2+}$ concentration stimulates cell contraction and migration through the initiation and participation of cytoskeleton reorganization, such as activation of the $\mathrm{Ca}^{2+} /$ calmodulin (Pauly et al. 1995) and $\mathrm{Ca}^{2+} / \mathrm{RhoA}$ (Rao et al. 2001) signalling pathways, mediation of cadherin-catenin-associated interaction (Guo et al. 2003) and the Ras superfamily of small GTP (guanosine triphosphate)-binding proteins.

Another candidate gene also up-regulated by the action of SJZPS was that coding for acid-sensing ion channels, protongated cation channels (ASIC1). This gene is a member of the ASIC subfamily (Waldmann \& Lazdunski, 1998) that shares certain identity (approximately 20-25\%) with the subunit of the epithelial $\mathrm{Na}$ channel with similar topological domains and intracellular termini. Both of its subunits (ASIC1 $\alpha$ and ASIC $\beta$ ) were shown to associate with the formation of $\mathrm{Na}^{+}$-selective ion channels (Fyfe et al. 1998), but with different permeability for $\mathrm{Ca}^{2+}$ (Chen et al. 1998). ASIC might provide certain means for controlling the $\mathrm{Ca}^{2+}$ entry pathway as well as modulating neuronal activity (Waldmann \& Lazdunski, 1998). Furthermore, ASIC was found to participate in the formation of mechanosensitive ion channels that were implicated to be associated with the cytoskeleton (Price et al. 2000).

Surprisingly, a proto-oncogene (JUND) was found to be overexpressed in the SJZPS-induced IEC-6 cell system. JunD is a member of the Jun family, which consists of three members (c-jun, JunB and JunD) and they are all cellular transcription factors. They occupy a central role in cellular signal transduction and regulation of proliferation (Lamph et al. 1988) through their binding to specific DNA sequences as homodimers or heterodimers with Fos proteins, forming a complex called activator protein-1 (Curran \& Vogt, 1992). Previous studies showed that c-jun, JunB and JunD mRNA levels were elevated several times after vascular injury and such focal expression indicates the consequences of the initiation of DNA synthesis and migration after vascular injury. Increasing evidence has confirmed that c-jun and JunB are involved in the initiation of cell cycle and proliferation. Conversely, the role of JunD in cell proliferation is still unclear. Some data showed that JunD could slow down cell proliferation (Hirai et al. 1989; Ryder et al. 1989; Li et al. 2002) while some reports still proposed that it could induce cell proliferation. There are two processes involved in the achievement of mucosal restitution: the rapid removal of damaged cells by sloughing followed by the migration of adjacent cells and the replacement of lost cells through cell proliferation. The former occurs within $1 \mathrm{~h}$ while the latter process may begin around $16 \mathrm{~h}$ after injury (Silen, 1987). So the over-expression of JunD can be explained in the sense that it transiently slowed down the proliferation of IEC- 6 cells, while the cells were actively migrating under the influence of SJZPS by modulating the $\mathrm{K}$ channels and cytosolic $\mathrm{Ca}^{2+}$ concentration.

In the present study, we used IEC- 6 cells as a cellular model to elicit the protective and restitution effects of SJZPS on gastrointestinal lining. Our results indicate that SJZPS not only exerts a stimulatory effect on the proliferation of IEC- 6 cells, but also restores the recovery of IEC- 6 cells after treatment with indomethacin. In addition, we also found that SJZPS can increase the cell migration rate after wounding. In applying the DNA microarray technology to study differential gene expression of SJZPS-induced IEC-6 cells, we discovered increased expression of a group of genes that are related to $\mathrm{K}$ and ion channels. The microarray data were confirmed by RT-PCR.

In research on traditional Chinese medicine formulations, the pharmacological actions of polysaccharides are usually neglected 
probably owing to the complexity of their chemical nature. However, with the introduction of DNA microarray technologies into the study of Chinese medicine, it is possible to correlate the effects of the herbal compound at the gene level (Watanabe et al. 2001; Bonham et al. 2002; Sadava et al. 2002; Iizuka et al. 2003). SJZD is a classic Chinese herbal formula with tonic properties on the gastrointestinal system. In this work we have demonstrated that polysaccharides of SJZD can significantly enhance the in vitro migration and proliferation of IEC-6 cells. These data provide further evidence to support the therapeutic value of SJZD in traditional Chinese medicine formulations.

\section{Acknowledgements}

This work was supported by Hong Kong Baptist University (Faculty Research Grant FRG//00-01/II-75-P). The authors also thank Dr Zhou H. for assisting in statistical analysis; Dr Jiang Z. H., Ms Wang J. R., Ms Shen X. L. and Mr Fu I. J. for determination of sugar composition and content.

\section{References}

Bilato C, Pauly RR, Melillo G, Monticone R, Gorelick-Feldman D, Gluzband YA, Sollott SJ, Ziman B, Lakatta EG \& Crow MT (1995) Intracellular signaling pathways required for rat vascular smooth muscle cell migration. Interactions between basic fibroblast growth factor and platelet-derived growth factor. J Clin Invest 96, 1905-1915.

Bjarnason I, Hayllar J, MacPherson AJ \& Russell AS (1993) Side effects of nonsteroidal anti-inflammatory drugs on the small and large intestine in humans. Gastroenterology 104, 1832-1847.

Bonham M, Arnold H, Montgomery B \& Nelson PS (2002) Molecular effects of the herbal compound PC-SPES: identification of activity pathways in prostate carcinoma. Cancer Res 62, 3920-3924.

Cario E, Jung S, Harder D'Heureuse J, Schulte C, Sturm A, Wiedenmann B, Goebell H \& Dignass AU (2000) Effects of exogenous zinc supplementation on intestinal epithelial repair in vitro. Eur J Clin Invest 30, 419-428.

Chang R (2002) Bioactive polysaccharides from traditional Chinese medicine herb as anticancer adjuvants. J Altern Complement Med 8, $559-565$.

Chen C, England S, Akopian AN \& Wood JN (1998) A sensory neuronspecific, proton-gated ion channel. Neurobiology 95, 10240-10245.

Chen GZ \& Fu D (1996) Effect of jiawei sijunzi decoction on migrating myoelectric complex in $8 \mathrm{~Gy}$ irradiated rats. Zhongguo Zhong Xi Yi Jie He Za Zhi 16, 221-223.

Chun H, Shin DH, Hong BS, Cho WD, Cho HY \& Yang HC (2002) Biochemical properties of polysaccharides from black pepper. Biol Pharm Bull 25, 1203-1208.

Curran T \& Vogt P (1992) Transcriptional Regulation. New York: Cold Spring Harbor Press.

Dignass AU \& Podolsky DK (1995) Growth factors and cytokinase in inflammatory bowel disease: injury and healing in the epithelium. In Inflammatory Bowel Diseases, pp. 375-383 [GNJ Tygat, JFWM Bartelsman and SJH van Deventer, editors]. Dordrecht: Kluwer Academic Publishers.

Ding SZ, Lam SK, Yuen ST, Wong BC, Hui WM, Ho J, Guo X \& Cho CH (1998) Prostaglandin, tumor necrosis factor alpha and neutrophils: causative relationship in indomethacin-induced stomach injuries. Eur $J$ Pharmacol 348, 257-263.

Fleischmann BD, Fleischmann BK, Punt JA, Gaulton G, Hashimoto Y \& Kotlikoff MI (1993) Control of resting membrane potential by delayed rectifier potassium currents in ferret airway smooth muscle cells. J Physiol 469, 625-638.

Fyfe GK, Quinn A \& Canessa CM (1998) Structure and function of the Mec-ENaC family of ion channels. Semin Nephrol 18, 138-151.
Guo L, Dong ND, Xiong AB, Liu ZY, Liu CR \& He XC (2003) An experimental study on the prevention and treatment of postburn intestinal injury and bacterial translocation by Sijunzi decoction in scalded rats. Zhonghua Shao Shang Za Zhi 19, 89-93.

Haranaka K, Satomi N, Sakurai A, Haranaka R, Okada N \& Kobay M (1985) Antitumor activities and tumor necrosis factor producibility of traditional Chinese medicine and crude drug. Cancer Immunol Immunother 20, 1-5.

Hegde P, Qi R, Abernathy K, Gay C, Dharap S, Gaspard R, Hughes JE, Snesrud E, Lee N \& Quackenbush J (2000) Concise guide to cDNA microarray analysis. Biotechniques 29, 548-562.

Himmel HM, Whorton AR \& Strauss HC (1993) Intracellular calcium, currents, and stimulus-response coupling in endothelial cells. Hypertension 21, 112-127.

Hirai SI, Ryseck RP, Mechta F, Bravo R \& Yaniv M (1989) Characterization of junD: a new member of the jun proto-oncogene family. EMBO $J$ 8, 1433-1439.

Iizuka N, Oka M, Yamamoto K, Tangoku A, Miyamoto K, Miyamoto T, Uchimura S, Hamamoto Y \& Okita K (2003) Identification of common or distinct genes related to antitumor activities of a medicinal herb and its major component by oligonucleotide microarray. Int J Cancer 107, 666-672.

Kimura RE, Arango V \& Lloyd-Still J (1998) Indomethacin and pancreatic enzymes synergistically damage intestine of rats. Dig Dis Sci $\mathbf{4 3}$, $2322-2332$.

Kiyohara H, Matsumoto T \& Yamada H (2002) Intestinal immune system modulating polysaccharides in a Japanese herbal (Kampo) medicine, Juzen-Taiho-To. Phytomedicine 9, 614-624.

Lacy ER (1988) Epithelial restitution in the gastrointestinal tract. J Clin Gastroenterol 10, 72-77.

Lamph WW, Wamsley P, Sassone-Corsi P \& Verma IM (1988) Induction of proto-oncogene JUN/AP-1 by serum and TPA. Nature 334, $629-631$.

Langmead L \& Rampton DS (2001) Herbal treatment in gastrointestinal and liver disease - benefits and dangers. Aliment Pharmacol Ther 15, 1239-1252.

Larkai EN, Smith JL, Lidsky MD \& Graham DY (1987) Gastroduodenal mucosa and dyspeptic symptoms in arthritic patients during chronic nonsteroidal anti-inflammatory drug use. Am $J$ Gastroenterol 82, $1153-1158$.

Li L, Li J, Rao JN, Li M, Bass BL \& Wang JY (1999) Inhibition of polyamine synthesis induces p53 gene expression but not apoptosis. Am J Physiol Cell Physiol 276, C946-C954.

Li L, Liu L, Rao JN, Esmaili A, Strauch ED, Bass BL \& Wang JY (2002) JunD stabilization results in inhibition of normal intestinal epithelial cell growth through P21 after polyamine depletion. Gastroenterology 123, 764-779.

Lin PF (1988) Antitumor effect of Actinidia chinensis polysaccharide on murine tumor. Zhongghua Zhong Liu Za Zhi 10, 441-444.

Liu L, Zhou H, Wang PX \& Hu YJ (2000) Influence of total polysaccharide extracted from Sijunzi decoction on the intestinal mucosa associated lymphoid tissues of mice. Zhougguo Mianyixue Zazhi 17, 204-206.

Lowry O, Rosebrough NH, Farr AL \& Randall RJ (1951) Protein measurement with the Folin phenol reagent. J Biol Chem 193, 265-275.

McCormack SA, Viar MJ \& Johnson LR (1992) Migration of IEC-6 cells: a model for mucosal healing. Am J Physiol 263, G426-G435.

McCormack SA, Viar MJ \& Johnson LR (1993) Polysaccharides are necessary for cell migration by a small intestinal crypt cell line. Am J Physiol 264, G367-G374.

McCormack SA, Blanner PM, Zimmerman BJ, Ray R, Poppleton HM, Patel TB \& Johnson LR (1998) Polyamine deficiency alters EGF receptor distribution and signaling effectiveness in IEC-6 cells. Am J Physiol 274, C192-C205.

McCormack SA, Ray R, Blanner PM \& Johnson LR (1999) Polyamine depletion alters the relationship of F-actin, G-actin, and thymosin beta 4 in migrating IEC-6 cells. Am J Physiol 276, C459-C468. 
Miller GL (1959) Use of dinitrosalicylic acid reagent for determination of reducing sugar. J Anal Chem 31, 426-430.

Moore R, Carlson S \& Madara JL (1989) Rapid barrier restitution in an in vitro model of intestinal epithelial injury. Lab Invest 60, $237-244$.

Moore TM, Brough GH, Babal P, Kelly JJ, Li M \& Stevens T (1998) Store-operated calcium entry promotes shape change in pulmonary endothelial cells expressing Trp1. Am J Physiol 275, L574-L582.

Mosmann T (1983) Rapid colorimetric assay for cellular growth and survival: application to proliferation and cytotoxicity assays. J Immunol Methods 65, 55-63.

Nilius B, Vianna F \& Droogmans G (1997) Ion channels in vascular endothelium. Апnи Rev Physiol 59, 145-170.

Ou M (1993) Chinese-English Manual of Common-used Prescription in TCM. Guangdong: Guangdong Science \& Technology Publishing House.

Pauly RR, Bilato C, Sollott SJ, Monticone R, Kelly PT, Lakatta EG \& Crow MT (1995) Role of calcium/calmodulin-dependent protein kinase II in the regulation of vascular smooth muscle cell migration. Circulation 91, 1107-1115.

Price MP, Lewin GR, McIlwrath SL, et al. (2000) The mammalian sodium channel BNC1 is required for normal touch sensation. Nature $\mathbf{4 0 7}$, $1007-1011$.

Putney JWJ \& Bird GS (1993) The inositol phosphate-calcium signaling system in nonexcitable cells. Endocr Rev 14, 610-631.

Quaroni A, Wands J, Trelstad RL \& Isselbacher KJ (1979) Epithelial cell cultures from rat small intestine: characterization by morphologic and immunologic criteria. J Cell Biol 80, 248-265.

Rao JN, Li L, Golovina VA, Platoshyn O, Strauch ED, Yuan JX \& Wang JY (2001) CA2 + -RhoA signalling pathway required for polyaminedependent intestinal epithelial cell migration. Am J Physiol Cell Physiol 280, C993-C1007.

Rao JN, Platoshyn O, Li L, Guo X, Golovina VA, Yuan JX \& Wang JY (2002) Activation of $\mathrm{K}^{+}$channels and increased migration of differentiated intestinal epithelial cells after wounding. Am J Physiol Cell Physiol 282, C885-C898.

Ryder K, Lanahan A, Perez-Albuerne E \& Nathans D (1989) Jun-D: a third member of the jun gene family. Proc Natl Acad Sci USA 86 , $1500-1503$.

Sadava D, Ahn J, Zhan M, Pang ML, Ding J \& Kane SE (2002) Effects of four Chinese herbal extracts on drug-sensitive and multidrug-resistant small-cell lung carcinoma cells. Cancer Chemother Pharmacol 49, 261-266.

Silen W (1987) Gastric mucosal defense and repair. In Physiology of the Gastrointestinal Tract, pp. 1055-1069, [LR Johnson and J Christense, editors]. New York: Raven Press.

Staub AM (1965) Removal of proteins - Sevag method. Methods Carbohydr Chem 5, 5-6.

Tarnawski A, Tanoue K, Santos AM \& Sarfen IJ (1995) Cellular and molecular mechanisms of gastric ulcer healing. Is the quality of mucosal scar affected by treatment? Scand J Gastroenterol 210, 9-14.

Tsien RW \& Tsien RY (1990) Calcium channels, stores, and oscillations. Annu Rev Cell Biol 6, 715-760.

Waldmann R \& Lazdunski M (1998) H(+)-gated cation channels: neuronal acid sensors in the NaC/DEG family of ion channels. Curr Opin Neurobiol 8, 418-424.

Wang JY, Wang J, Golovina VA, Li L, Platoshyn O \& Yuen JXJ (2000) Role of $\mathrm{K}^{+}$channel expression in polyamine-dependent intestinal epithelial cell migration. Am J Physiol Cell Physiol 278, C303-C314.

Watanabe CM, Wolffram S, Ader P, Rimbach G, Packer L, Maguire JJ, Schultz PG \& Gohil K (2001) The in vivo neuromodulatory effects of the herbal medicine Ginkgo biloba. Proc Natl Acad Sci USA 98 6577-6580.

Xu HM, Xie ZH \& Zhang WY (1994) Immuomodulatory function of polysaccharide of Hericium erinaceus. Zhongguo Zhong Xi Yi Jie He Za Zhi 14, 427-428.

Zhao AG, Zhao HL, Jin XJ, Yang JK \& Tang LD (2002) Effects of Chinese Jianpi herbs on cell apoptosis and related gene expression in human gastric cancer grafted onto nude mice. World $J$ Gastroenterol 8, 792-796.

Zhong WR, Huang YX \& Cui JP (1997) Clinical study on modified sijunzi decoction in treating intestinal metaplasia of gastric mucosa. Zhongguo Zhong Xi Yi Jie He Za Zhi 17, 462-464. 